\title{
Relevance Of Sensor And Chemical Technology In Water Quality Monitoring
}

\author{
Richa Khare*, Ajita Pathak and Smriti Khare \\ Amity University, Lucknow \\ richa.khare2005@gmail.com
}

Article History: Received: 10 November 2020; Revised 12 January 2021 Accepted: 27 January 2021; Published online: 5 April 2021

\begin{abstract}
This paper is related to the monitoring of water quality and others problem related to water distribution systems for common people. Our target is to develop such sensors and other chemical methods to calculate the exact value of different parameters related to water at $\mathrm{A}$ very low cost. In this paper, we present our studies about $\mathrm{pH}$ value, conductivity, temperature, turbidity, BOD and DO. The results of our experiments show that the minimum value system is efficient of monitoring these high impact contaminants at fairly low concentrations.
\end{abstract}

\section{Keywords}

Standard of Water detection, measuring method, turbidity sensor, multi-sensor system, BOD, DO, $\mathrm{pH}$ detection.

\section{INTRODUCTION}

Problem of impure drinking water is arising on regular basis (1). In order to assess the water quality variations, of various parameters, we are using different techniques and methods for calculating the exact value of different parameters of water (2). Especially, biological oxygen demand, dissolved oxygen, $\mathrm{pH}$ values and other advances that have been considered for monitoring drinking water quality and to produce contamination free water and secure human health (3). Variation in water quality is caused by changes in the concentration of inputs to the water body system. These changes may be manmade, natural or random (4). We have used a set of sensors to develop a system for water quality measurements. It is capable to measure certain parameters: $\mathrm{pH}$, temperature, dissolved oxygen, conductivity and turbidity (5). The process employs thick film technology. Although development of sensor technology for water monitoring $(6,7)$ is not new, our endeavour is to develop a low cost, easy to use and accurate instrument to indicate and control water quality

\section{EXPERIMENTAL}

The system consists of various sensors in hybrid thick film technology which is capable of water quality monitoring. One side electrodes are set which are in direct contact of water and other side sensors are protected from water. Electrodes are given different layers as per the requirement and condition. First layer is made up of silver/platinum, second layer of gold, third layer of pure silver, used as reference electrode. Fourth layer remains resistive for conductivity, $\mathrm{pH}$ and dissolved oxygen. Fifth layer is protective layer. Sixth and seventh layers are graphite and silver chloride respectively for ion selective sensors. Last layers are membrane for dissolved oxygen sensors. 
For the measurement of $\mathrm{pH}$ a thick film electrode with screen printing of ruthenium oxide is used. The $\mathrm{pH}$ response time is lower than the 5-6 seconds, which makes it efficient and fast. Coating of $\mathrm{TiO}_{2}$ on $\mathrm{RuO}_{2}$ electrodes gives a linear function of log of the dissolved oxygen concentration (8). Other parameter is turbidity for which thick film turbid meter assembly is used. The GaAlAs SHF426 electroluminescent diode is used as an emitting element and infrared NPN SHH325FA phototransistor is used as a receiving element. Moreover a current converter using OP amp is used. Two receivers possessing $90^{\circ}$ separation with each other collects direct radiations as well as dispersed radiation by non-dissolved particles. The semiconductor temperature sensor LM50D with SOT-23 has a sensitivity of $10 \mathrm{mV} /{ }^{\circ} \mathrm{C}$ and can work in the temperature range of $40{ }^{\circ} \mathrm{C}-125^{\circ} \mathrm{C}$.

The measurement system is completed by a PCB containing the circuits for the signal conditioning of each sensor used and a general purpose analogue and digital acquisition card of a computer. This provides a suitable graphic user interface and with information on screen.

The whole system lodged on PVC housing can be incorporated in a small portable/integrated system for water quality monitoring. The system is of reduced cost, reduced size and fast enough to be used for wide range of applications.

\section{RESULT AND DISCUSSION}

Our study based on the location of water and the different amount of impurities present in the form of other components.

Table 1. Near industry waste water

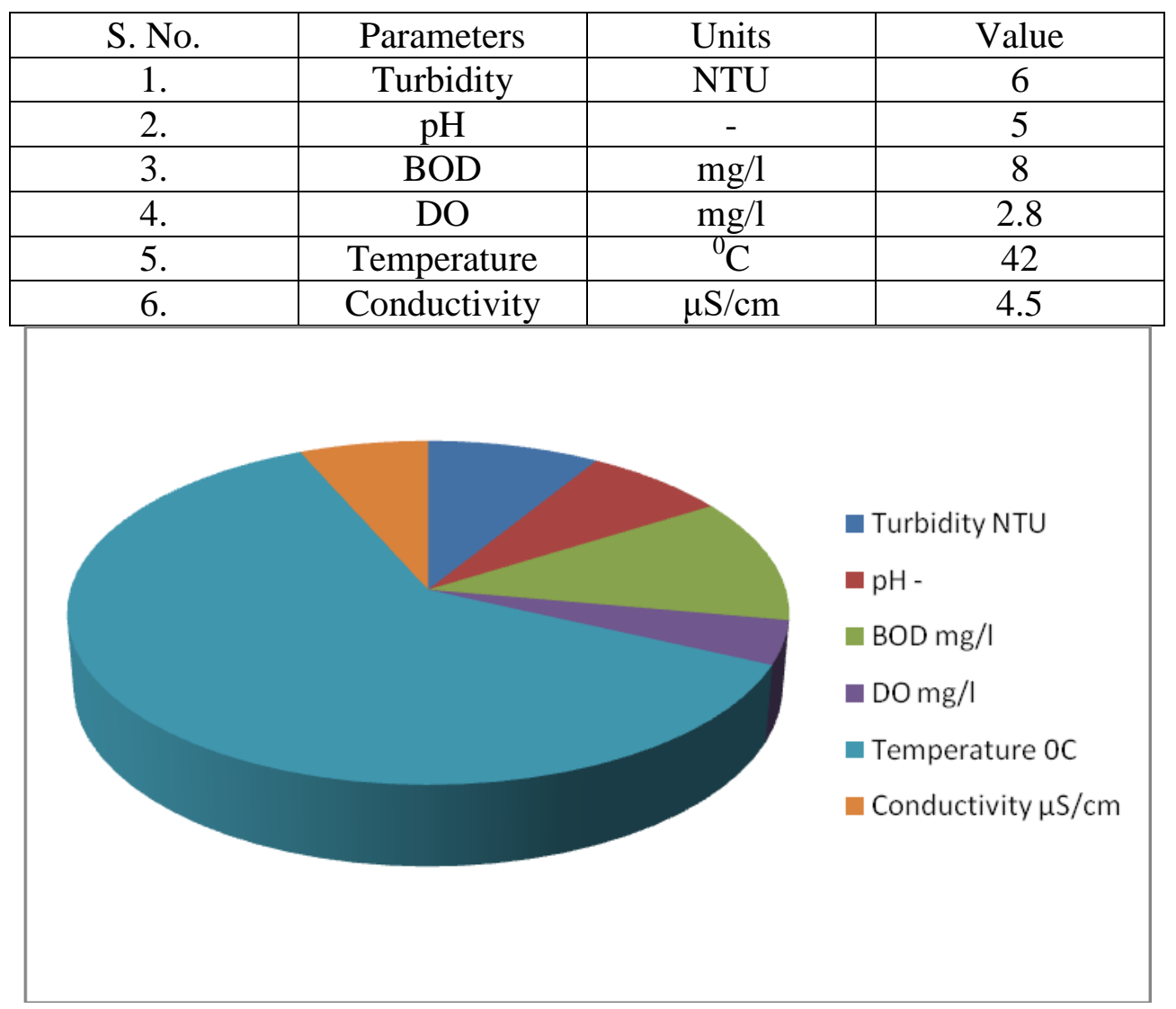

Figure 1. Near industry waste water 
Table 2. Near thermal waste water

\begin{tabular}{|c|c|c|c|}
\hline S. No. & Parameters & Units & Value \\
\hline 1. & Turbidity & NTU & 7.1 \\
\hline 2. & $\mathrm{pH}$ & - & 6.8 \\
\hline 3. & BOD & $\mathrm{mg} / \mathrm{l}$ & 9 \\
\hline 4. & $\mathrm{DO}$ & $\mathrm{mg} / \mathrm{l}$ & 2.6 \\
\hline 5. & Temperature & ${ }^{0} \mathrm{C}$ & 48 \\
\hline 6. & Conductivity & $\mu \mathrm{S} / \mathrm{cm}$ & 5.5 \\
\hline
\end{tabular}

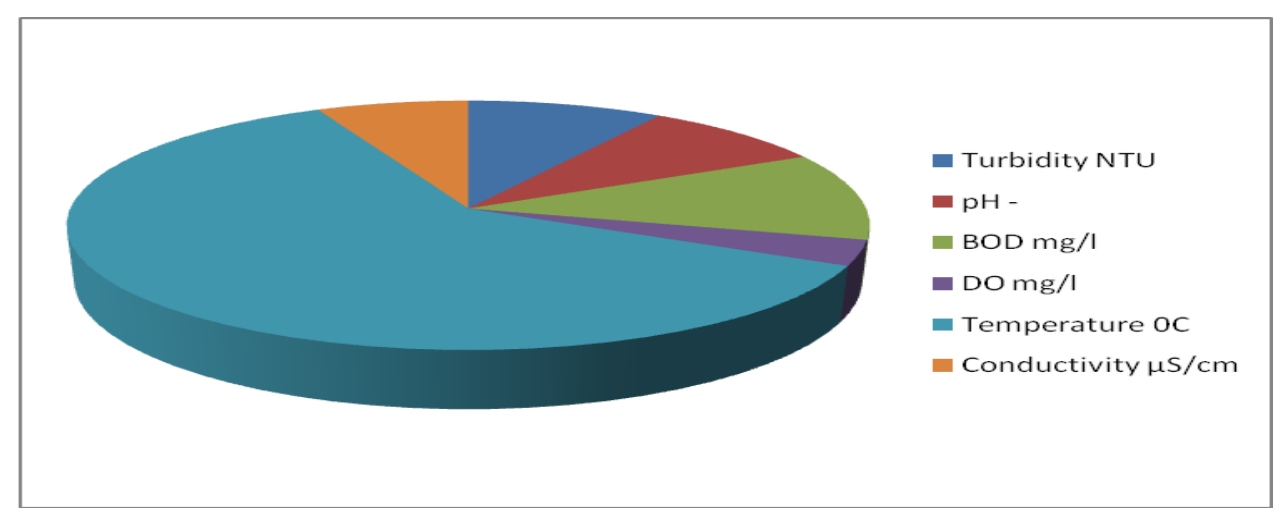

Figure 2. Near thermal waste water

Table 3. Far from industrial waste water

\begin{tabular}{|c|c|c|c|}
\hline S. No. & Parameters & Units & Value \\
\hline 1. & Turbidity & NTU & 5.1 \\
\hline 2. & $\mathrm{pH}$ & - & 6.5 \\
\hline 3. & $\mathrm{BOD}$ & $\mathrm{mg} / \mathrm{l}$ & 5 \\
\hline 4. & $\mathrm{DO}$ & $\mathrm{mg} / 1$ & 7.5 \\
\hline 5. & Temperature & ${ }^{0} \mathrm{C}$ & 32 \\
\hline 6. & Conductivity & $\mu \mathrm{S} / \mathrm{cm}$ & 5 \\
\hline
\end{tabular}

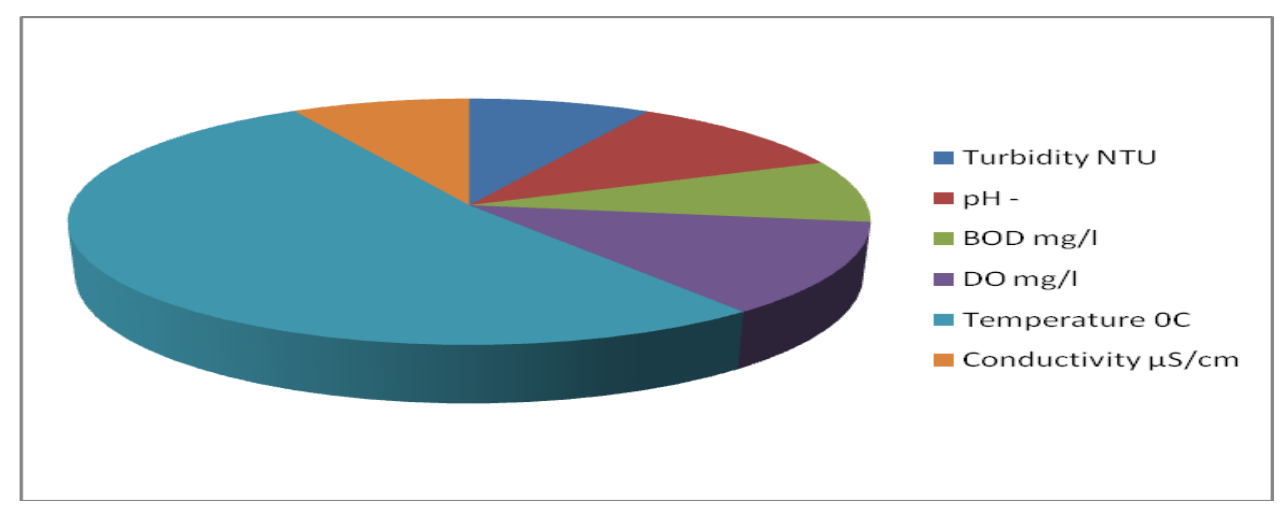

Figure 3. Far from industrial waste water 
According to our study, we found that the turbidity in industrial water is higher in comparison to less polluted water and drinking water (The WHO established that the turbidity of drinking water should not be more than 5 NTU, and should ideally be below 1 NTU). Level of DO is higher in normal water as compared to polluted water whereas BOD is higher in polluted water. The $\mathrm{pH}$ value of more polluted water is basic, in this study we found that far industrial waste water has higher DO level in comparison to near thermal waste water and industrial waste water. Temperature of far industrial waste water is low in comparison to thermal waste water and industrial waste water. There is no as such effect on conductivity according to the site as it varies due to presence of ions.

Hybrid thick film technology enabled us to study the different parameters of water such as the value of BOD, DO, conductivity, turbidity etc. After getting all these results, we are continuing our efforts to purify such water by employing $\mathrm{RO}$ and other methods of distillation.

\section{REFERENCES}

1. R. Khare and Smriti, IOSR Journal of Applied Chemistry, 2 (4), 37 (2012).

2. J. Pandey, R. Khare and Smriti, International Journal of Advanced Research in Engineering and Applied Sciences, 5(8), 44 (2016).

3. R. Khare, A. Pathak and Smriti, Pollution Research, 37 (4), 1044 (2018).

4. Smriti, R. Khare, N. Misra and Shujjaudin, Pollution Research, 37 (1), 218 (2018).

5. R. Khare and Smriti, World. Journal of Pharmacy and Pharmaceutical Sciences, 5 (1), 1080 (2016).

6. M. V. Storey, B. Gaag and B. P.Burns, Advances in on-line drinking water quality monitoring and early warning systems, 45(2), 741 (2011).

7. J. Ramprabu and C. Paramesh, IJETTCS, 3(5), 748 (2014).

8. R. Martinez-Mañez, J. Soto, J. Lizondo-Sabater, E. García-Breijo, L. Gil, J. Ibáñez, I. Alcaina and S. Alvarez, Sensors and Actuators B, 101, 295 (2004). 